\author{
Ahmed A Al-Ali \\ BDS, MSc (Lect) \\ Luma M Al-Nema \\ BDS, MSc (Assist Lect) \\ Ibtehal H Al-Zubaidy \\ BDS, MSc (Assist Lect)
}

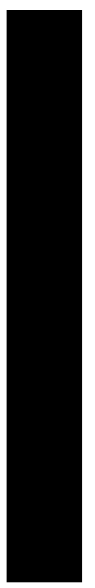

\section{Surface Porosity of Different Investment Materials with Different Mixing Tech- niques}

\author{
Department of Prosthetic Dentistry \\ College of Dentistry, University of Mosul
}

\begin{abstract}
Aims: To evaluate and compare the number and surface area of surface porosities of different dental investment materials by using two mixing techniques. Materials and Methods: Two mixing techniques; manual and mechanical were used to prepare specimens for four dental investment materials: Biosint Supra, Rema Exakt, Rematitan Plus, and Deguvest soft. Computer programs are used to measure the number and surface area of the porosities to compare among them. ANOVA, Duncan multiple range test in addition to T-test were carried out to determine the significant difference at $P<0.05$. Results: In relation to the surface area of the porosities, there are high significant differences among the investment materials tested, and high significant difference is presented between the two mixing techniques tested with the manual mixing technique and showing higher value than the mechanical vacuum mixing technique. In relation to the number of porosities, there are no significant difference among the investment materials tested, but there are very high significant differences between the two mixing techniques tested with the manual mixing technique and showing higher value than the mechanical vacuum mixing technique. Conclusions: the number and surface area of the surface porosities differ from the different materials used, and differ in the same material by changing the mixing technique.
\end{abstract}

Key words: Porosity, Investment, Mixing technique.

Al-Ali AA, Al-Nema LM, Al-Zubaidy IH. Surface Porosity of Different Investment Materials with Different Mixing Techniques. Al-Rafidain Dent J. 2009; 9(2): 307-314.

Received: 5/1/2009 Sent to Referees: 8/1/2009

Accepted for Publication: 1/3/2009

\section{INTRODUCTION}

Dental investment materials are being used for a growing number of different material-forming procedures in the construction of an increasing variety of dental devices. The major requirement of all dental investment materials is that they survive the various material-forming procedures without fracture, deformation or surface degradation in order to achieve accurately fitting dental restorations ${ }^{(1)}$.

The porosity or pore volume of a material has been defined as the total proportion of air spaces contained between the solid particles of which the body is composed ${ }^{(2)}$. Porosity differs from permeability in that porosity includes all voids while permeability is restricted to interconnecting voids ${ }^{(3)}$.
The mixing or spatulation of many dental materials is a troublesome and unpredictable process because of the introduction of porosities caused by the nature of the water/ powder or paste/paste interaction. Such problems may also result from the mechanical action of the mixing device. Ideally, completely homogenous materials would be desirable ${ }^{(4)}$. The investment has a significant influence on the surface roughness of the cast part. The surface roughness of the cast part approaches that of the surface of the mold. Therefore, a very smooth surface of the mold with only a few pores is necessary ${ }^{(5)}$. The aims of the present research are to evaluate and compare the number and surface area of surface porosities of different 
dental investment materials by using two mixing techniques manual and mechanical.

\section{MAERIALS AND MEHODS}

Four dental investment materials are used : 1.Biosint Supra, Degussa, Germany, for CoCr casting technique.

2.Rema Exakt, DENTAURUM, Germany, for $\mathrm{Co}-\mathrm{Cr}$ casting technique.

3.Rematitan Plus investment, DENTAURUM, Germany, for titanium casting technique.
4.Deguvest soft, Degussa, Germany, precision investment for the complete range of precious metal casting technique.

Two mixing techniques were used: manual mixing with hand spatulation, and mechanical vacuum mixing using vacuum with a mixing machine (Multivac4, Degussa, Germany).Technical data were explained in Table (1).

Table(1): Materials and technical data.

\begin{tabular}{cccc}
\hline Material & Mixing time & P:L ratio & Set time \\
\hline Biosint Supra & $1.5-2$ minutes & $73 \mathrm{~g}: 11 \mathrm{ml}$ & $30 \mathrm{~min}$ \\
Rema Exakt & 60 seconds & $73 \mathrm{~g}: 11 \mathrm{ml}$ & $30 \mathrm{~min}$ \\
Rematitan Plus & 60 seconds & $75 \mathrm{~g}: 12 \mathrm{ml}$ & $40 \mathrm{~min}$ \\
Deguvest soft & 90 seconds & $100 \mathrm{~g}: 17 \mathrm{ml}$ & $10 \mathrm{~min}$ \\
\hline
\end{tabular}

Ten specimens for each material were constructed. Specimens prepared by pouring investment material into cylindrical, plastic molds with a height of $40 \mathrm{~mm}$ and a diameter of $20 \mathrm{~mm}$ according to ADA specification. The handling of material (powder-liquid ratio and setting time) followed according to manufacturer instructions provided with each material Table (1). Digital balance ( A\&d company limited, Japan) was used to weight the powder and a graduated cylinder was used to measure the liquid. The molds were vibrated gently while being filled using electrical vibrator (Qualy Dental, England) then a glass plate was placed on top of the over-filled molds and pressed flush with uniform spatula with the mold ends to ensure flat and smooth end.

All specimens were inspected under reflective microscope (Altay, Turkey) with a magnification power (x15). The pictures were captured in the computer using special digital camera connected via a cable to the computer; and using advanced computer program for movies capturing (Snazzi Movie Mill), The saved fractographs were inspected for porosities and the discovered porosities' area and number were calculated using AutoCAD program (advanced program for designing by computer) by drawing a fixed-dimension square shape around the sample's perimeter, and drawing cloud around the irregularly shaped porosity's area, and finding the area by finding the area of an object option available in the program, to exclude the magnification factor the percentage of the porosity's area to the cross section area were found. This method of measuring is similar to a method used by $\mathrm{Al}-\mathrm{Niaimi}{ }^{(6)}$ who measured the surface porosity of $\mathrm{Co}-\mathrm{Cr}$ alloy.

Statistically mean values and standard deviation were calculated. Mean values of the tested materials were compared with ANOVA followed by Duncan multiple range test to determine the significant difference at $\mathrm{P}<0.05$ level of significance, while $\mathrm{T}$-test was carried out to determine the significant difference between the two mixing techniques at $\mathrm{P}<0.05$ level of significance.

\section{RESULS}

Means for the combination of all groups (porosity surface area and porosity number) are shown in Table (2). In determining the surface area of porosities, comparision among all the subgroushowed very high significant difference between them (Table 3). 
Table (2): Means for all groups(porosity surface area and porosity number).

\begin{tabular}{ccc}
\hline Material \&technique & porosity surface area \% & porosity number/unit area \\
\hline Biosint Supra-manual & 6.7473 & 5.4000 \\
Biosint Supra-mechanical & 3.5330 & 4.0000 \\
Rema Exakt-manual & 12.4718 & 7.8000 \\
Rema Exakt-mechanical & 1.5964 & 2.4000 \\
Rematitan Plus- manual & 2.4242 & 6.4000 \\
Rematitan Plus-mechanical & 1.6129 & 4.2000 \\
Deguvest soft-manual & 2.4364 & 4.8000 \\
Deguvest soft-mechanical & 0.6737 & 1.6000 \\
\hline
\end{tabular}

Table (3):ANOVA test for all groups(porosity surface area).

\begin{tabular}{cccccc}
\hline Significance & F-value & Mean Square & Df* & Sum of Squares & \\
\hline 0.000 & 10.922 & 76.410 & 7 & 534.873 & Between Groups \\
& & 6.996 & 32 & 223.873 & Within Groups \\
& & & 39 & 758.746 & Total \\
\hline
\end{tabular}

*degree of freedom.

The (Rema Exakt-manual) showed the largest value(12.4718\%). There were no significant difference between (Biosint Supra-manual) and (Biosint Supramechanical) but they both showed singnifi- cantly lower value than the (Rema Exaktmanual). (Biosint Supra-manual) showed significantly higher value than the remaining variables in which there were no significant difference (Figure 1).

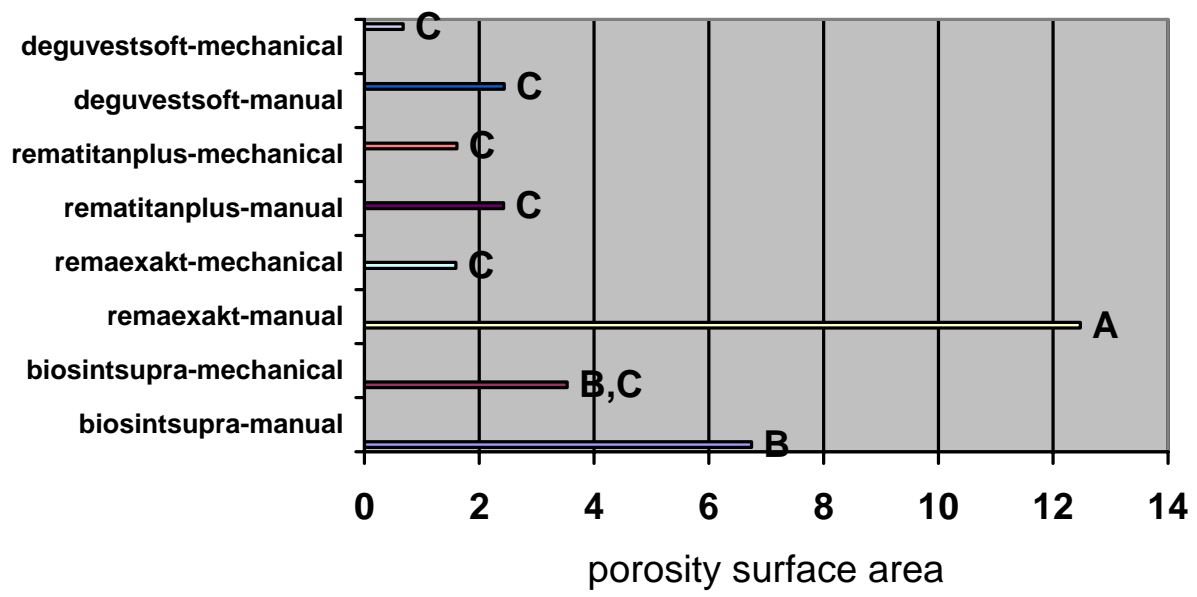

Figure (1): Duncan Multiple Rang Test for all groups(porosity surface area). 
In determining the number of porosities, comparision among all subgroups showed very high significant difference between them (Table 4).

Table (4): ANOVA test for all groups(porosity number).

\begin{tabular}{cccccc}
\hline Significance & F-value & Mean Square & Df* & Sum of Squares & \\
\hline 0.000 & \multirow{2}{*}{6.080} & 20.368 & 7 & 142.575 & Between Groups \\
& & 3.350 & 32 & 107.200 & Within Groups \\
& & & 39 & 249.775 & Total \\
\hline
\end{tabular}

*degree of freedom

There were no significant difference in the number of porosities per unit area between Rema Exakt-manual, Rematitan Plus-manual, and Biosint Supra-manual, but they showed significantly higher number of porosity than the other groups. There were no significant difference between: Rematitan Plus-manual, Biosint Supra- manual, Deguvest soft-manual, Rematitan Plus-mechanical, and Biosint Supramechanical but these subgroups showed significantly higher number of porosities than Rema Exakt-mechanical subgroup. Deguvest soft-mechanical subgroup showed the significantly lowest number of porosities among all the subgroups(Figure 2).

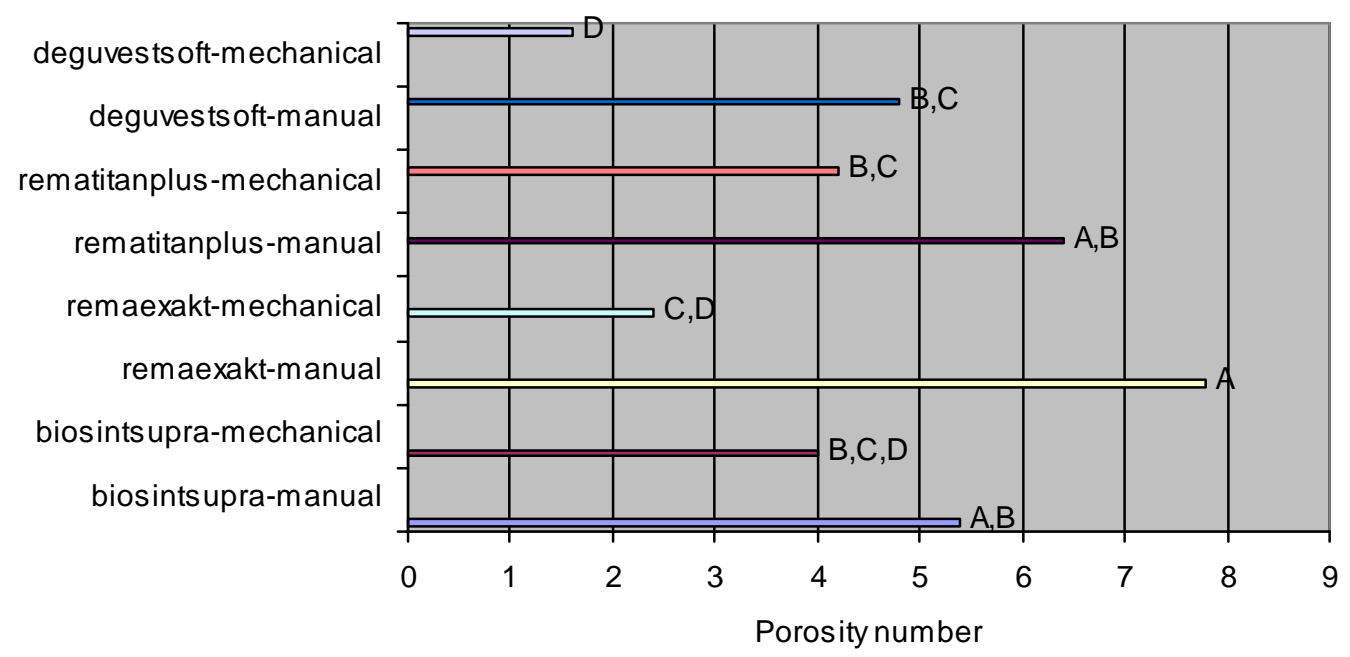

Figure (2): Duncan Multiple Rang Test for all groups(porosity number). 
When comparing the investment materials to each other, there were high significant difference between them in relation to the surface area of the porosities $(\mathrm{P}=0.01)$, (Table 5).

Table (5): ANOVA test for the materials(porosity surface area).

\begin{tabular}{cccccc}
\hline Significance & F-value & Mean Square & Df* & Sum of Squares & \\
\hline 0.010 & 4.411 & 67.980 & 3 & 203.939 & Between Groups \\
& & 15.411 & 36 & 554.806 & Within Groups \\
& & & 39 & 758.746 & Total \\
\hline
\end{tabular}

*degree of freedom

The Rema Exakt showed significantly higher value than Rematitan Plus and Deguvest soft. There were no significant differences between Rema Exakt and Biosint Su- pra. There were no significant difference among Biosint Supra, Rematitan Plus, and Deguvest soft (Figure 3).

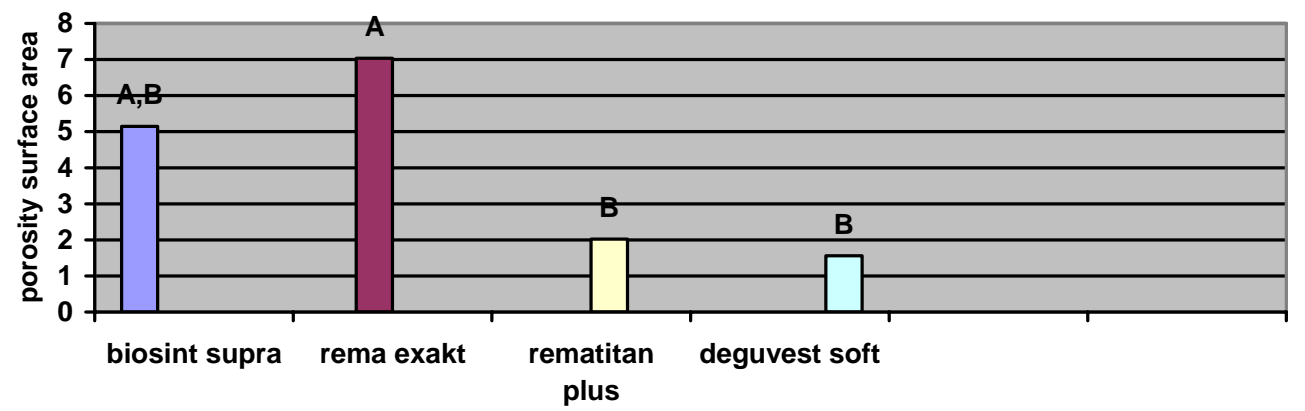

Figure (3): Duncan Multiple Rang Test for materials (porosity surface area)

In relation to the number of porosities, when comparing the investment materials to each other, there were no significant differ- ence among them $(\mathrm{P}=0.242)$ (Table 6, Figure4).

Table (6): ANOVA test for the materials (porosity number).

\begin{tabular}{cccccc} 
Significance & F-value & Mean Square & Df* & Sum of Squares & \\
\hline 0.242 & 1.459 & 9.025 & 3 & 27.075 & Between Groups \\
& & 6.186 & 36 & 222.700 & Within Groups \\
& & & 39 & 249.775 & Total \\
\hline
\end{tabular}

*degree of freedom 


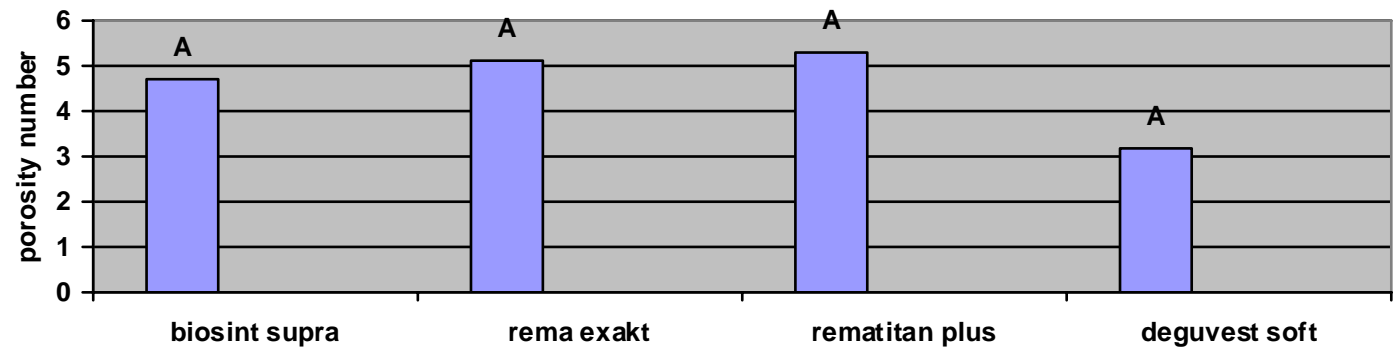

Figure (4): Duncan Multiple Rang Test for materials (porosity number)

In relation to the two mixing techniques, when determining the surface area of the porosities, there were high significant differences between them $(\mathrm{P}=0$.003) (Table 7), with the manual method showed higher value(6.0199\%) than the mechanical method (1.8540\%)(Figure5).

Table (7): T-test for the techniques (porosity surface area).

\begin{tabular}{|c|c|c|c|c|c|c|}
\hline \multicolumn{2}{|c|}{$\begin{array}{c}\text { 95\% Confidence Interval of } \\
\text { the Difference }\end{array}$} & \multirow{2}{*}{$\begin{array}{l}\text { Std. Error } \\
\text { Difference }\end{array}$} & \multirow{2}{*}{$\begin{array}{c}\text { Mean } \\
\text { Difference }\end{array}$} & \multirow{2}{*}{$\begin{array}{l}\text { Significance } \\
\text { (2-tailed) }\end{array}$} & \multirow{2}{*}{ Df* } & \multirow{2}{*}{ T-value } \\
\hline Upper & Lower & & & & & \\
\hline 6.74217 & 1.58977 & 1.24096 & 4.1660 & 0.003 & 21.622 & 3.357 \\
\hline
\end{tabular}

*degree of freedom

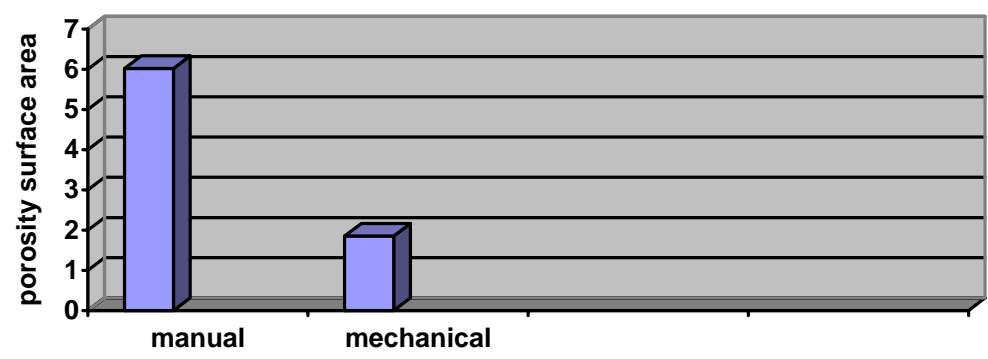

Figure (5): Means for the techniques (porosity surface area)

In relation to the two techniques, when determining the number of the porosities, there were very high significant differences between them $(\mathrm{p}=0.000)$ (Table 8), with the manual method showed higher value(6.1) than the mechanical method (3. 05) (Figure $6)$. 
Table (8): T-test for the techniques (porosity number).

\begin{tabular}{|c|c|c|c|c|c|c|}
\hline \multicolumn{2}{|c|}{$\begin{array}{c}\text { 95\% Confidence Interval of } \\
\text { the Difference }\end{array}$} & \multirow{2}{*}{$\begin{array}{l}\text { Std. Error } \\
\text { Difference }\end{array}$} & \multirow{2}{*}{$\begin{array}{l}\text { Mean Dif- } \\
\text { ference }\end{array}$} & \multirow{2}{*}{$\begin{array}{l}\text { Significance (2- } \\
\text { tailed) }\end{array}$} & \multirow{2}{*}{ Df* } & \multirow{2}{*}{$\begin{array}{c}\mathbf{T}- \\
\text { value }\end{array}$} \\
\hline Upper & Lower & & & & & \\
\hline 4.35019 & 1.74981 & .64226 & 3.0500 & .000 & 38 & 4.749 \\
\hline
\end{tabular}

*degree of freedom

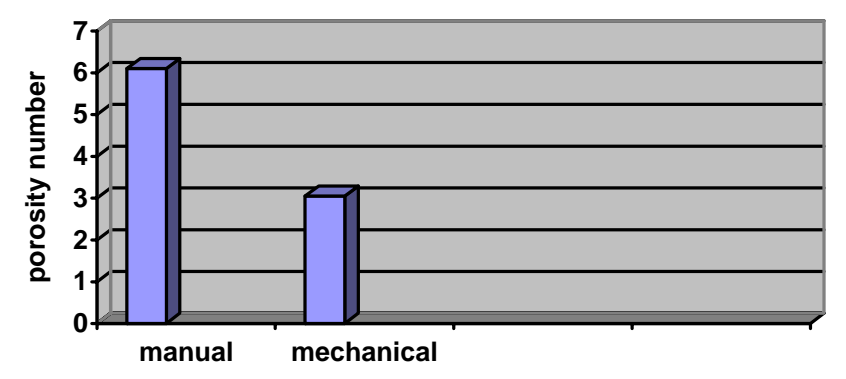

Figure (6): Means for the techniques (porosity number)

\section{DISCUSSION}

Porosity is simply the proportion of the bulk volume material occupied by voids ${ }^{(7)}$. The difference among the investment materials in relation to the number of porosities and the surface area of porosity can be related to several factors depending on chemical composition, refractory particle size and handling techniques ${ }^{(8,9)}$. The use of either mechanical or hand spatulation as well as increased and decreased pressures during investment preparation affects the incidence and size of pores and consequently the strength of the material ${ }^{(10)}$. Lacey et al ${ }^{(11)}$ showed that varying the powder/liquid ratio of investment will affect the incidence and size of bubbles within the material.

Rema Exact having the highest surface area of surface porosities while Deguvest soft having the least surface area of surface porosities. The reason may be that Rema Exact had the highest powder /liquid ratio, while Deguvest soft had the lowest powder /liquid ratio and these are the manufacturer's instructions (Table 1).

Hand mixing and mechanical vacuum mixing techniques were selected for this investigation as it has been shown that they produce the widest variation in pore surface area distribution ${ }^{(9)}$. This research demonstrated that handling techniques have a direct influence on the number and surface area of the pores produced in dental investment material. This come in agreement with Johnson ${ }^{(12)}$ Chandler et al ${ }^{(13)}$ and Lacey et $a l^{(11)}$.

The results of the present research showed that there was a significant difference in surface area of porosities between the investment materials in relation to the handling techniques. The manual or hand mixed samples appeared to have greater surface area of porosity than mechanical vacuum-mixed samples. Therefore the mechanical vacuum mixing technique resulted in smallest pore surface area. This result come in agreement with AbuHassan et al ${ }^{(3)}$ Juszczyka et $a l^{(9)}$ Scrabeck et $a l^{(4)}$.

The present research showed that hand mixing technique exhibited greater number of porosities .This may be due to air bubbles trapped during the mixing process becoming incorporated into the set investment .Also, the pressure acts by reducing the surface area of air bubbles present in the investment as the pressure may force the particles of the investment closer together. This result come in agreement with AbuHassan et $a l^{(3)}$, Scra- 
beck et al (4) , Juszczyka et al ${ }^{(8)}$, and Juszczyka et al ${ }^{(9)}$.

For the reasons mentioned above, mechanical spatulation under vacuum should be performed for dental investment materials to reduce surface porosities and to improve the potential for accurate replication and casting.

In spite of this, the investment should be internally porous enough to permit the air or other gases in the mold cavity to escape easily during the casting procedure. The materials that are so closely packed and they are virtually porosity free, there is a danger of back pressure building up which will cause the mold to be incompletely filled or the casting to be porous ${ }^{(14)}$.

\section{CONCLUSIONS}

In relation to the surface area of the porosities, there are high significant differences among the investment materials tested, and high significant difference is present between the two mixing techniques tested, with the manual technique showing higher value than the mechanical technique.

In relation to the number of porosities, there are no significant difference among the investment materials tested, but there are very high significant differences between the two mixing techniques tested, with the manual technique showing higher value than the mechanical technique.

\section{REFERENCES}

1. Juszczyk AS, Radford DR, Curtis RV. Deformation of phosphate-bonded investment materials at elevated temperatures. Dent Mat. 2007; 23: 579-585

2. Grimshaw RW. The chemistry and Physics of Clays and Allied Ceramic Material. London, Ernest Benn. 1971.

3. AbuHassan MI, GlynJones IC, Hallsworth AS. Porosity Determination of Cast Invest- ment by a Wax-Infiltration Technique. $J$ Dent. 1989;17:195-198.

4. Scrabeck JG ,Eames WB. Spatulation Methods and Porosities in Investments and Impression Material. J Prosthet Dent. 1986; 55:332-334.

5. Baumeister G, Hauelt J, Rath S, Ruprecht R . Microcasting. Advanced Micro and Nanosystems. 2005; 4:359-367.

6. Al-Niaimi AJ. Effect of Laser Welding on the Tensile Strength and Radiographic Analysis of Co-Cr Repaired Joints. M.Sc. thesis, College of Dentistry, University of Mosul.2008.

7. Tidy DC. The Permeability of Dental Casting Investments. J Dent. 1974; 2: 227233.

8. Juszczyka AS, Radford DR and Curtis RV. Sensitivity of disc rupture strength test to air bubble pores in phosphate-bonded materials at elevated temperatures. Dent Mat. 2002; 18: 255-262.

9. Juszczyka AS, Radford DR, and Curtis $\mathrm{RV}$. The influence of handling techniques on the strength of phosphate bonded investments. Dent Mat. 2000; 16: 23-32.

10. Luk HK, Darvell BW. Effect of burnout temperature on strength of phosphatebonded investments. J Dent. 1997; 25: 15360.

11. Lacey AM, Mora A, Boonsiri I. Incidence of bubbles on samples cast in phosphatebonded investment. J Prosthet Dent. 1985; 54: 367-369.

12. Johnson A. The effect of five investingtechniques on air bubble entrapment and casting nodules. Int J Prosthodont.1992; 5: 424433.

13. Chandler HT, Fisher WT, Brudvik JS and Bottiger G. Vacum-air pressure investing. $J$ Prosthet Dent. 1973; 29: 225-227.

14. Rejab LT. Effect of wax burn-out heating temperature on the compressive strength of casting dental alloy investment. Accepted for publication Al-Rafidain Dent J. 2008.(in press). 